OPEN ACCESS

Edited by:

Andrea Gomez-Zavaglia,

National University of La

Plata, Argentina

Reviewed by:

Edy Sousa de Brito,

Embrapa Agroindústria Tropical, Brazil

Guillermo Alfredo Picó,

Institute of Biotechnological and

Chemical Processes Rosario

(IPROBYQ), Argentina

*Correspondence:

Enrico Doria

enrico.doria@unipv.it

Specialty section

This article was submitted to

Sustainable Food Processing,

a section of the journal

Frontiers in Sustainable Food Systems

Received: 02 April 2021

Accepted: 31 August 2021

Published: 27 September 2021

Citation:

Doria E, Boncompagni E, Marra A, Dossena $M$, Verri $M$ and Buonocore $D$

(2021) Polyphenols Extraction From Vegetable Wastes Using a Green and

Sustainable Method.

Front. Sustain. Food Syst. 5:690399.

doi: 10.3389/fsufs.2021.690399

\section{Polyphenols Extraction From Vegetable Wastes Using a Green and Sustainable Method}

\author{
Enrico Doria*, Eleonora Boncompagni, Antonio Marra, Maurizia Dossena, Manuela Verri \\ and Daniela Buonocore
}

Laboratory of Pharmacology, Department of Biology and Biotechnology, University of Pavia, Pavia, Italy

Food systems have the potential to support human health, respecting the environmental sustainability principles. Food sustainability, enclosed in the concept of environmental sustainability, involves different aspects, including the recycling of food waste derived from the agri-food production chain, the use of biotechnologies ensuring the sustainability of the recovery processes of bioactive compounds from food waste and, last but not least, the awareness of having to consume and waste less food. Food loss and waste is generated during the whole supply chain, from production to household utilization. The utilization of agricultural wastes as an abundant, renewable and low-cost source for the production of high value-added products is currently explored. The bioactive compounds present in these sources have been proved to possess a wide range of biological activities; therefore, research is needed into the application of environmentally friendly traditional and advanced techniques with low production costs in the extraction, isolation and purification of phytochemical compounds from agricultural wastes in high yields and at maximal quality. Authors of this manuscript propose and discuss an innovative and sustainable extraction system of polyphenols from vegetable waste, based on an enzymatic pre-treatment coupled with a solid-liquid extraction by using a particular extractor (Naviglio Estrattore ${ }^{\circledR}$ ). This extraction system, organic solvent free, allowed to extract relevant amount of polyphenols (flavonoids in particular) from several vegetable waste products.

\section{Keywords: food system sustainability, food waste, food waste recycling, bioactive compounds, enzymatic extraction, polyphenols}

\section{INTRODUCTION}

\section{Food Loss and Waste in the Food Supply Chain}

The reduction of food loss and waste is considered by the United Nations and many international institutions as one of the main ways to proceed toward the protection of the environment and for the well-being of humanity, as also reaffirmed by the UN 2030 Agenda for Sustainable Development [ODD-ONU Italia (unric.org)]. Furthermore, food waste is a key determinant, inter alia, of the loss of biodiversity, the dispersion of greenhouse gases in the atmosphere, the pollution of water, soil and other resources (www.isprambiente.gov.it). The main global factors, responsible of the large amount of food waste, are: 
- the increase in the world population and urbanization,

- the great availability of fossil energy sources,

- the economic and cultural diffusion of mass agro-industrial systems,

- the transformation of (food) lifestyles

- assigning a relatively low economic and socio-cultural value to food (Clapp, 2002; FAO, 2011; Gille, 2012).

Several evidences also show that the increase of food waste, especially when produced during sales and consumption, is directly proportional to the increase of the levels of economic development $(29,30)$. It is extremely hard to exactly quantify the lost and wasted food in the world today and, even more difficult, is to prevent the food losses. Moreover, currently, there is not much research in the area, which is quite surprising considering that food production must significantly increase to meet future global demand. Not much attention appears to be paid to current global food supply chain losses (Gustavsson et al., 2011). The issue of food loss and waste represents an important topic in the efforts to reduce hunger, raise income and improve the food security in the world's poorest countries. Food losses have a relevant impact on food security for poor people, on food quality and safety, on economic development and on the environment. According to the Food and Agriculture Organization (FAO), 1.300.000.000 tons of food gets yearly lost or wasted in the all the world, representing approximately one-third of the edible parts of food produced for human consumption.

Food loss and waste is generated throughout the entire supply chain: the $54 \%$ of total loss and waste occurs during the upstream processes (including production and postharvest) and $46 \%$ of total loss and waste occurs during the downstream processes (including processing, distribution, and consumption) (Mirabella et al., 2014). In particular, in developing countries more than $40 \%$ of these food losses occur at post-harvest and processing levels, while in industrialized countries, around the $45 \%$ of the food losses occurs at retail and consumer levels. In Europe every year, $280-300 \mathrm{~kg}$ per capita of food at different stages are wasted and lost, mainly concerning the vegetables and fruit sector (Gustavsson et al., 2011; FAO et al., 2014). According to the report by the FAO of the United Nations (FAO et al., 2014), 45\% of fruit and vegetable wastes and byproducts from the fruit and vegetable processing industry are generated around the world throughout the entire food supply chain. Most of fruit and vegetable wastes is disposed in landfills or rivers, which represents a threat to the environment due to their high biodegradability, leachate, and methane emissions (Misi and Forster, 2002). However, these resources have a great potential to be used for the recovery of value-added products (Wadhwa and Bakshi, 2013).

\section{Food Waste Recovery Improves Sustainability of Food System}

A food system assembles different aspects (environment, people, inputs, processes, infrastructures, institutions, etc.) and activities related to the production, processing, distribution, preparation, and consumption of food, and their socioeconomic and environmental outcomes (HLPE, 2014). As mentioned before, food waste has an important impact on food and nutrition security, food quality and safety, natural resources, and environmental protection. For these reasons, management of food loss and waste, with their co- and by-products have already attracted the attention of food scientists and industry over the last decades (Galanakis, 2015). In fact, recently several scientific reports, relevant to food waste and treating methods, were published, especially including strategies for reduction of waste production, the valorisation of co- and by-products, and improvement of waste management. This increasing attention is mainly due to the following reasons:

a) the growing environmental concerns,

b) the necessity to minimize the impact of waste on human health,

c) the high costs of waste disposal that are limiting the profits of the food industry,

d) the growing interest toward benefits deriving from potentially marketable components present in food wastes and coproducts (Laufenberg et al., 2003).

For all these reasons, unlike the traditional linear economic model, based on a "take-make-consume-throw away" pattern, a circular economy model is concepted and based on sharing, leasing, reuse, repair and recycling, in an (almost) closed loop, where the contained products and materials are highly valued (Bourguignon, 2016).

Agriculture not only is ensuring global food security for over 7 billion people around the world, but also plays an important role in supporting and promoting the development of other industries, such as nutraceuticals, pharmaceuticals and cosmetics. In particular, agri-food industry produces a large amount of wastes and residues along the whole supply chain, still containing a significant quantity of valuable bioactive compounds, such as polyphenols (phenolic acids, flavonoids, proanthocyanidins, anthocyanins, glycosides...), carotenoids, saponins, tannins, alkaloids, sterols, steroids, triterpenes, peptides and carbohydrates properties (Moure et al., 2001; Llorach et al., 2002; Zhang et al., 2017), which, as largely demonstrated, possess several biological activities, including antioxidant, antibacterial, antifungal, antiviral, antimicrobial, antidiabetic, anticancer, antidiarrhoeal, antihypertensive, antimutagenic, anti-inflammatory, anticholesterol and protective properties of cardiocirculatory system (Balasundram et al., 2006; Santana-Méridas et al., 2012; Nguyen, 2017). Increasing the yield of the target compounds adopting the most appropriate food waste recovery strategies, the economic value gained from them could be maximized. Moreover, the recovery of high added-value material could result in the development of innovative products and/or materials (Galanakis, 2015) and highlights the importance of science-based innovation to improve the sustainability of food system (Defra, 2006). There is another important aspect to consider: the recovery of food wastes and its valuable bioactive compounds could also help in promoting the viability and diversity of rural and urban economies, contributing to create new job opportunities (Galanakis, 2015). Finally, reducing food waste, by recovering compounds with biological activity present in the waste, represents an important solution to increase the 
sustainability of the food production system, also contributing to the reduction of waste management costs which can represent a serious problem, especially for smaller producers.

\section{Sustainability of Extraction Processes}

Food by-products and wastes contain highly complex components with a relevant biological and economical value, although these residual materials generally present a lower concentrations of valuable compounds respect to the initial sources. Fruit and vegetable wastes, in particular, contain a significant amount of biologically active compounds (valueadded products) like polyphenols, glucosinolates, dietary fibers, essential oils, pigments, organic acids, etc. (Baiano, 2014; Kumar et al., 2017). In addition, in some vegetable materials, the content of bioactive compound in by-products is higher than in their major parts. These compounds can be extracted, purified, and characterized using emerging technologies, allowing to develop new commercial applications in food and non-food (pharmaceutical, biomedical, cosmetic, etc.) areas (Galanakis et al., 2012). Even in the process of recovering food waste, the reduction of energy and the optimization of raw materials can significantly reduce costs and at the same time increase the environmental sustainability of the food system. An efficient food waste recovery process has two meanings; firstly, it is necessary to use only that type of material that otherwise would have been thrown away and, secondly, to use / process that material as efficiently as possible, using technologies and extraction methods functional to the type of compounds to be extracted. Food wastes are generated in different forms and compositions, according to regional, seasonal, and processing characteristics in each case (Gustavsson et al., 2011). This implies that the cost for the processing could increase, as well as the recovery yield can decrease. Moreover, food wastes are susceptible to microbial contamination and require both proper preservation and fast treatment. Following all these considerations, the development of an economically feasible, sustainable, and safe recovery of bio-active compounds from food residue must take into account several parameters such as the abundance and distribution of food wastes (related to the presence of industry), the set-up of methodologies providing the highest recovery yield of different compounds, the utilization of green solvents, the preservation of the biological properties of selected compounds from source to final product, waste minimization prior to the recovery process, the application of environmentally friendly traditional and advanced techniques with low production costs in the extraction, isolation and purification of phytochemical compounds from agricultural wastes in high yields and at maximal quality (Varzakas et al., 2016; Nguyen, 2017). Hence, technological advances in extraction, separation and identification have been developed to produce natural products with potent biological activity (Van Lanen and Shen, 2006; Wang and Weller, 2006). The biggest research challenge is now the identification and set up of the best "extraction" conditions, i.e., the condition that improve release of the bioactive compounds from the vegetable matrix in which they are encased. The recovery process of bioactive compounds from fruit and vegetable waste includes several important stages in succession: preparation of dried samples, extraction process, production of the powder extract, isolation and purification by chromatography (Pham, 2017). Each of these different phases involves the use of different technologies, aimed at the recovery of specific molecules with different physico-chemical characteristics; however, it is important that, in compliance with sustainability criteria, each of these processes has a reduced environmental impact both in terms of energy and the use of solvent. Regarding the extraction methods, conventional methods, commonly found in literature, are very numerous and long to list but the main used are liquidliquid or solid-liquid extraction, primarily based on the use of organic solvents. Nowadays, in respect with "Circular Economy" principles, alternative and innovative extraction systems are used, depending on the characteristics of target compounds; the main emerging techniques, considered innovative, rapid, reproducible, cost/benefit, and clean, are the following:

\section{- Ultrasound Assisted Extraction (UAE) \\ - Pulsed Electric Field (PEF) \\ - Microwave assisted Extraction (MAE) \\ - Pressurized Liquid Extraction (PLE) \\ - Supercritical Fluid Extraction (SFE) \\ - Enzyme Assisted Extraction (EAE)}

Except for solvent extraction, whose sustainability is depending on the type of used solvent, the other listed technologies are considered "green," although the cost of some equipment used in the extraction plants is sometimes high. Enzyme Assisted Extraction is perhaps the most environmentally and economically sustainable of those listed above. The main mechanism behind EAE involves cell wall degrading enzymes such as glucanase and pectinase which weaken or deconstruct the cell wall, making intracellular compounds more accessible for extraction.

\section{STRATEGY FOR POLYPHENOLS EXTRACTION FROM VEGETABLE WASTE MATERIAL-AN EXPERIMENTAL EVIDENCE}

An eco-friendly extraction system, alternative to conventional solvent-based and complex physical methods, was set up by the authors of this papers and it will be described below.

Some vegetable waste, obtained from manufacturing industry, were used as source of bioactive compounds such as polyphenols. Since many polyphenols are found to form complexes with plant cell-walls structures (proteins and carbohydrates), often recalcitrant to degradation, the treatment of plant materials with enzymatic mixtures containing cellulases, hemicellulases and pectinases, promotes the hydrolytic degradation of cell wall polymers, thereby favoring the release of secondary metabolites (Khandare et al., 2011; Puri et al., 2012). Cell wall polysaccharides, in fact, are known to interact with various polyphenols, modifying their bioaccessibility and bioavailability. The EAE treatment of the food waste is then complemented by a solid-liquid (water) extraction with the 
Naviglio Estrattore $\AA$ (NE), a system based on the generation of a negative pressure gradient between the outside and inside of solid matrix, followed by a sudden reinstatement of the initial balanced conditions. This pressure gradient leads to the forced extraction of compounds from the solid matrix in the aqueous phase. The preceding enzymatic treatment is expected to enhance the amount of extracted polyphenolic compounds.

Vegetable wastes [Petroselinum crispum (Mill.) (parsley), Brassica oleracea L. italica var. (broccoli), Brassica oleracea L. botrytis var. (cauliflower), Spinacia oleracea L. (spinach), Allium ampeloprasum L. (leek), Eruca vesicaria L. (rocket salad), Cichorium intybus L. (chicory)] were collected from farms and food processing industries (AOP Unolombardia consortium), located in Lombardia region (Italy). Enzymatic mixtures were obtained from Novozymes ${ }^{\circledR}$.

\section{Preparation of Samples, Enzymatic Pre-treatment and Extraction System}

The enzymatic mixtures (around $10 \mathrm{U} / \mathrm{ml}$ ) used in this work include hemicellulases, mixture of different cellulases and pectinase mixture, optimized after preliminary experiments in smaller scale. Fragments of the vegetable residues $(0.5 \mathrm{~cm})$, obtained by using a mill, were placed in the plastic trays with distilled water and an aliquot of each commercial enzymatic mixture in stirring conditions.

After this pre-treatment $\left(50^{\circ} \mathrm{C}\right.$ for $\left.3 \mathrm{~h}\right)$, the solid residue (around $5 \mathrm{~kg}$ ) from each material is placed in Naviglio Estrattore $^{\circledR}$ (N.E.), filled with only water, to complete the extraction process of polyphenols. The total amount of polyphenols and flavonoids was then measured using classical colorimetric methods (Folin-Ciocolteau and aluminum chloride methods, respectively), and the identification of the main polyphenols was performed by HPLC.

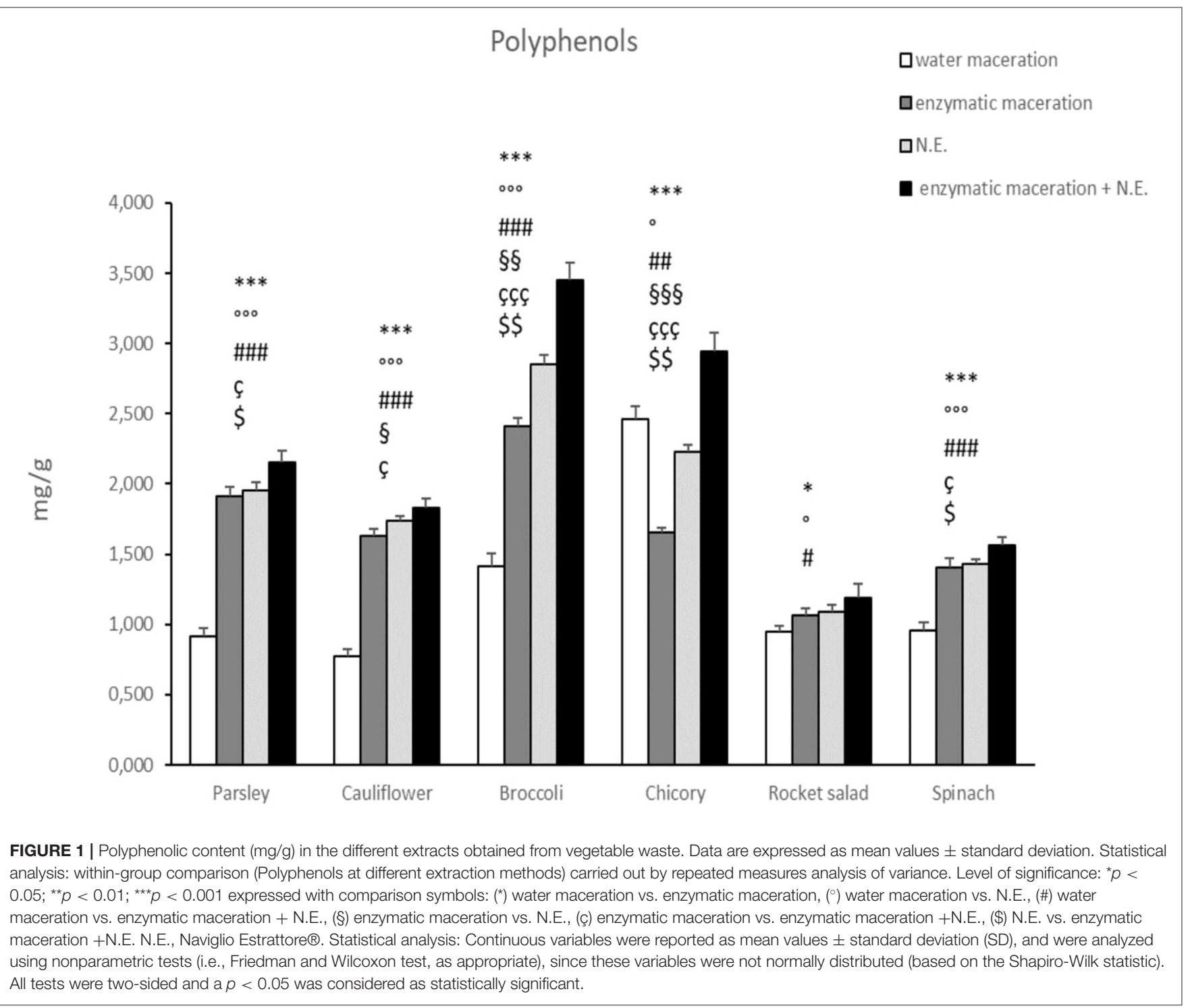




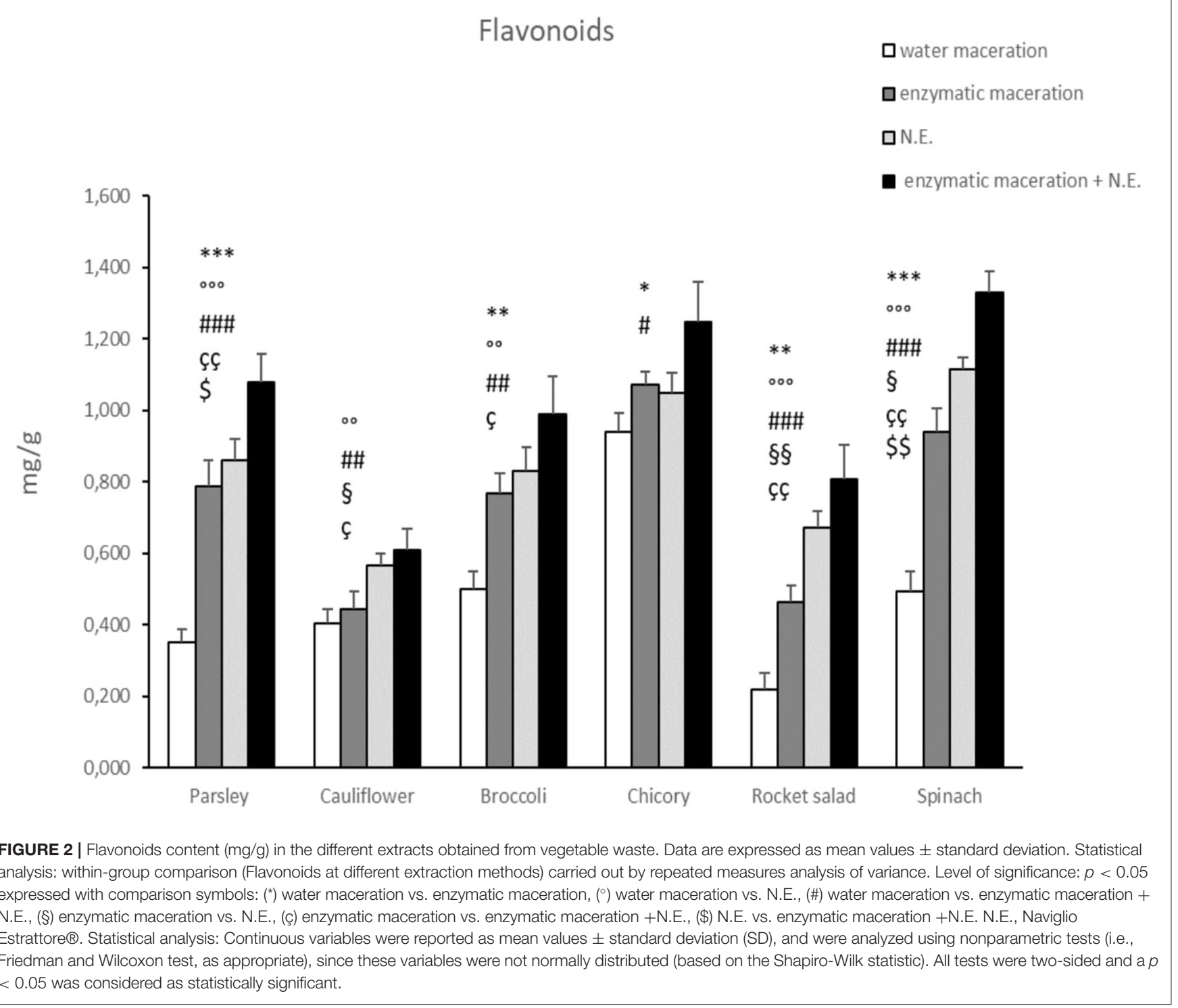

\section{RESULTS}

The total polyphenols content (TPC) and the total flavonoids content (TFC) contents are showed in Figures 1 and 2, respectively. The data are presented as $\mathrm{mg} / \mathrm{g}$ fresh weight $(\mathrm{FW})$, mean \pm standard deviation $(\mathrm{SD}, n=3)$. It is possible to observe as the enzymatic pre-treatment followed by the extraction with Naviglio Estrattore $\AA$ (N.E.), allowed to recover a higher concentration of polyphenols in all the plant waste material and especially from broccoli and chicory residues. In these two types of material, the amount of extracted polyphenols was clearly higher compared to that one observed using the only N.E. or the only enzymatic maceration. When the flavonoid concentration was tested, in all the examined material a noticeable increase using the N.E. after the enzymatic pre-treatment was measured (Figure 2). This observed difference in pre-treatment efficacy and in the phenolics extraction from vegetable waste is principally due to the biochemical characteristics and the cell wall composition of each material.

By using HPLC analysis, many phenolics were identified after the complete extraction system (enzymatic pre-treatment + N.E.) (Table 1).

The data obtained in this work are difficult to compare to those found in literature for different reasons. There are huge differences in vegetables polyphenol quantification depending on seasonal harvesting (Arabbi et al., 2004; Hertog et al., 2007), different cultivar (Heimler et al., 2007; Koh et al., 2009), the climate where they grow (Podsedek, 2007), the cultivation site (D'Acunzo et al., 2017) endogenous circadian rhythms (Soengas et al., 2018), soil and pest-control treatment (Valverde et al., 2015). Moreover, the use of solvent is a variable that greatly affects the extraction efficiency. In all the scientific papers regarding the extraction of polyphenols from the same vegetable matrix, several 
TABLE 1 | Phenolic compounds found in the vegetable extracts, obtained after the extraction process by N.E. following the enzymatic pre-treatment ( $n=3$ ).

\begin{tabular}{|c|c|c|c|c|c|c|}
\hline Polyphenols & $\begin{array}{l}\text { Broccoli } \\
\text { (mg/kg) }\end{array}$ & $\begin{array}{l}\text { Cauliflower } \\
\text { (mg/kg) }\end{array}$ & $\begin{array}{l}\text { Chicory } \\
\text { (mg/kg) }\end{array}$ & $\begin{array}{c}\text { Rocket salad } \\
\text { (mg/kg) }\end{array}$ & $\begin{array}{l}\text { Spinach } \\
\text { (mg/kg) }\end{array}$ & $\begin{array}{l}\text { Parsley } \\
\text { (mg/kg) }\end{array}$ \\
\hline Chlorogenic acid & $70 \pm 0.5$ & $320 \pm 15$ & $150 \pm 11$ & $100 \pm 13$ & $80 \pm 7$ & $10 \pm 0.9$ \\
\hline Catechins & $90 \pm 3$ & $130 \pm 8$ & $380 \pm 10$ & $20 \pm 2$ & $9 \pm 0.9$ & $70 \pm 5.5$ \\
\hline Caffeic acid & $40 \pm 5$ & - & $170 \pm 6$ & - & $6 \pm 0.5$ & $3 \pm 0.6$ \\
\hline Cumaric acid & - & $5 \pm 0.5$ & - & - & $5 \pm 0.3$ & $16 \pm 4$ \\
\hline Vitexin & $3 \pm 0.4$ & - & - & - & - & $30 \pm 7.5$ \\
\hline Orientin & $190 \pm 8$ & $16 \pm 2$ & - & - & $160 \pm 15$ & $22 \pm 5$ \\
\hline Rutin & $12 \pm 0.9$ & $9 \pm 0.8$ & - & - & - & $50 \pm 5$ \\
\hline Quercetin & - & - & $8 \pm 0.6$ & - & - & $13 \pm 0.8$ \\
\hline Cinnamic acid & - & 3 & - & - & - & $1 \pm 0.3$ \\
\hline Luteolin & - & - & $6 \pm 0.5$ & - & - & $8 \pm 0.5$ \\
\hline Kaempferol & - & - & $7 \pm 0.3$ & $7 \pm 0.5$ & $5 \pm 0.4$ & - \\
\hline
\end{tabular}

solvents like alcohols (methanol, ethanol), acetone, diethyl ether and ethyl acetate, often mixed with different proportions of water, were used.

\section{DISCUSSION}

The recovery of food by-products is a way to re-use the waste of the agri-food production chain, recovering their precious compounds, complying with the requirements of a circular economy, increasing the sustainability of the food production system. The set-up of innovative and sustainable extraction systems of natural products is currently a hot research topic involving different areas. The aim is to reduce or to eliminate the use of hazardous extraction solvents and ensure a safe and high quality of extract/product, in order to protect both the environment and consumers. Consequently, a sustainable and eco-friendly recovery of bioactive compounds from fruit and vegetable by-products for application in food, medical, cosmetic, pharmaceutical or agrochemicals industries is crucial to enhancing their added value and to reducing the pollution risk for the environment. For many years, the conventional techniques based on the use of solvent have been widely accepted, mainly because of their ease of use, efficiency, and wide-ranging applicability (Stalikas, 2007). In recent years, the use of organic conventional solvent is highly discouraged and legal limitations are becoming more and more rigorous, especially for food and pharmaceutical industry. Processes involving the use of organic solvents have a high negative impact on health and environment; beside this important aspect, the residues of solvent may also remain in the final products. This requires long additional purification steps and has repercussions on the total process cost. Additionally, by using pure organic solvents, very polar phenolic acids (benzoic, cinnamic acids) cannot be extracted completely. Therefore, the possibility to use important amounts of industrial by-products of agri-food chain to extract bio-active compounds as commercial goods with high marketing potential, in compliant with the current European legislation that strongly encourages the food industry to find new end-uses for by-/co-products, was explored in the experimental work presented in this paper.
Since the biggest research challenge is the identification of the best "extraction" conditions, in order to improve the release of bioactive compounds from the vegetable waste matrix reducing the use of organic solvents and respecting the principles of sustainability of the whole extraction process, the enzymatic pre-treatment coupled with aqueous extraction using Naviglio Estrattore ${ }^{\circledR}$ represent a sustainable strategy allowing to recover a good amount of phenolics, in particular. Due to the use of water as extraction solvent, phenolics compounds represent the main phytochemicals extracted and analyzed from the selected vegetable by-products.

\section{DATA AVAILABILITY STATEMENT}

The raw data supporting the conclusions of this article will be made available by the authors, without undue reservation.

\section{AUTHOR CONTRIBUTIONS}

ED: writing-original draft. ED and DB: work planning. EB and AM: performed research. MV, DB, and ED: data curation. DB: statistical analysis. $\mathrm{MD}$ and $\mathrm{DB}$ : funding acquisition. All authors contributed to the article and approved the submitted version.

\section{FUNDING}

This research study was partially funded by FEASR - 124 Rural Development program 2007-2013 "Cooperazione sviluppo prodotti, processi, tecnologie, settore agricolo, alimentare e forestale" Regione Lombardia- Project Code number E86D13000160004.

\section{ACKNOWLEDGMENTS}

We thank all the Institutions that supported this research: the Italian Ministry of Education, University and Research (MIUR), Dipartimenti di Eccellenza Program (2018-2022)-Dept. of Biology and Biotechnology L. Spallanzani. 


\section{REFERENCES}

Arabbi, P. R., Genovese, M. I., Lajolo, F. M. (2004). Flavonoids in vegetable foods commonly consumed in Brazil. J. Agric. Food Chem. 52(5):1124-1131.

Baiano, A. (2014). Recovery of biomolecules from food wastes-a review. Molecules 19, 14821-14842. doi: 10.3390/molecules190914821

Balasundram, N., Sundram, K., and Samman, S. (2006). Phenolic compounds in plants and agri-industrial by-products: antioxidant activity, occurrence, and potential uses. Food Chem. 99, 191-203. doi: 10.1016/j.foodchem.2005.07.042

Bourguignon, D. (2016). Closing the loop-new circular economy package. Eur. Parliament. Res. Serv. 1-9. https://www.europarl.europa.eu/RegData/etudes/ BRIE/2016/573899/EPRS_BRI\%282016\%29573899_EN.pdf

Clapp, J. (2002). Distancing of waste: overconsumption in a global economy. TIPEC Working paper 01/10, Trent International Political Economy Centre.

D’Acunzo, F., Giannino, D., Longo, V., Ciardi, M., Testone, G., Mele, G., et al. (2017). Influence of cultivation sites on sterol, nitrate, total phenolic contents and antioxidant activity in endive and stem chicory edible products. Int. J. Food Sci. Nutr. 68, 52-64. doi: 10.1080/09637486.2016.1221386

Defra (2006). Food Industry Sustainability Strategy. Available online at: http://www. defra.gov.uk/publications/files/pb11649-fiss2006-060411.pdf

FAO (2011). "Global food losses and food waste," in Extent, Causes and Prevention, eds. J. Gustavsson, C. Cederberg, U. Sonesson, R. Van Otterdijk, and A. Meybeck. Rome: Food and Agriculture Organization of the United Nations.

FAO, IFAD, and WFP (2014). The state of food insecurity in the world 2014. Strengthening the enabling environment for food security and nutrition. Rome: FAO. Available online at: http://www.fao.org/3/a-i4030e.pdf

Galanakis, C. M. (2015). Food Waste Recovery: Processing Technologies and Industrial Techniques.

Galanakis, C. M., Fountoulis, G., and Gekas, V. (2012). Nanofiltration of brackish groundwater by using a polypiperazine membrane. Desalination, Elsevier. 286, 277-284. doi: 10.1016/j.desal.2011.11.035

Gille, Z. (2012). From risk to waste: global food waste regimes. Soc. Rev. 60(S2), 27-46. doi: 10.1111/1467-954X.12036

Gustavsson, J., Cederberg, C., Sonesson, U., van Otterdijk, R., and Meybeck, A. (2011). Global Food Losses and Food Wastes: Extent, Causes and Prevention, Food and Agriculture Organization of the United Nations. Rome: ISBN.

Heimler, D., Isolani, L., Vignolini, P., Tombelli, S., and Romani, A. (2007). Polyphenol content and antioxidative activity in some species of freshly consumed salads. J. Agric. Food Chem. 55, 1724-1729 doi: 10.1021/jf0628983

Hertog, M. G. L., Hollman, P. C. H., and Katan, M. B. (2007). Content of potentially anticarcinogenic of flavonoids of 28 vegetables and 9 fruits commonly consumed in The Netherlands. J. Agric. Food Chem. 40, 2379-2383. doi: 10.1021/jf00024a011

HLPE (2014). Food Losses and Waste in the Context of Sustainable Food Systems. A report by the High Level Panel of Experts on Food Security and Nutrition of the Committee on World Food Security. Rome 2014. Available online at: http://www.fao.org/fileadmin/user_upload/hlpe/hlpe_documents/ HLPE_Reports/HLPE-Report-8_EN.pdf

Khandare, V., Walia, S., Singh, M., and Kaur, C. (2011). Black carrot (Daucus carota ssp. sativus) juice: processing effects on antioxidant composition and color. Food Bioprod. Process. 89, 482-486 doi: 10.1016/j.fbp.2010.07.007

Koh, E., Wimalasiri, K. M. S., Chassy, A. W., and Mitchell, A. E. (2009). Content of ascorbic acid, quercetin, kaempferol and total phenolics in commercial broccoli. J. Food Compos. Anal. 22, 637-643 doi: 10.1016/j.jfca.2009.01.019

Kumar, K., Yadav, A. N., Kumar, V., Vyas, P., and Dhaliwal, H. S. (2017). Food waste: a potential bioresource for extraction of nutraceuticals and bioactive compounds. Bioresour. Bioprocess.4:18. doi: 10.1186/s40643-017-0148-6

Laufenberg, G., Kunz, B., and Nystroem, M. (2003). Transformation of vegetable waste into value added products: (A) the upgrading concept; (B) practical implementation. Bioresour. Technol. 87, 167-198. doi: $10.1016 /$ S0960-8524(02)00167-0

Llorach, R., Espín, J. C., Tomás-Barberán, F. A., and Ferreres, F. (2002). Artichoke (Cynara scolymus L.) byproducts as a potential source of healthpromoting antioxidant phenolics. J. Agric. Food Chem. 50, 3458-3464. doi: 10.1021/jf0200570

Mirabella, N., Castellani, V., and Sala, S. (2014). Current options for the valorization of food manufacturing waste: a review. J. Clean. Prod. 65, 28-41 doi: 10.1016/j.jclepro.2013.10.051
Misi, S. N., and Forster, C. F. (2002). Semi-continuous anaerobic co-digestion of agrowastes. Environ. Technol. 23, 445-451 doi: 10.1080/09593332508618405

Moure, A., Jose, M., Cruz, J. M., Daniel Franco, D., Domínguez, J. M., JorgeSineiro, J., et al. (2001). Natural antioxidants from residual sources. Food Chem. 72, 145-171. doi: 10.1016/S0308-8146(00)00223-5

Nguyen, V. T. (2017). "Potential, uses and future perspectives of agricultural wastes," in Recovering Bioactive Compounds from Agricultural Wastes (Hoboken, NJ: Wiley), 1-32.

Pham, H. N. T. (2017). "Recovering bioactive compounds from fruit and vegetable wastes," in Recovering Bioactive Compounds from Agricultural Wastes (Chichester: Wiley), 81-99. doi: 10.1002/9781119168850.ch4

Podsedek, A. (2007). Natural antioxidants and antioxidant capacity of Brassica vegetables: a review. LWT-Food Sci. Technol. 40, 1-11. doi: 10.1016/j.lwt.2005.07.023

Puri, M., Sharma, D., and Barrow, C. J. (2012). Enzyme-assisted extraction of bioactives from plants. Trends Biotechnol. 30, 37-44 doi: 10.1016/j.tibtech.2011.06.014

Rapporto ISPRA, Istituto Superiore per la Protezione e la Ricerca Ambientale 279/2018. Available online at: Microsoft Word-RAPPORTO SPRECO ALIMENTARE_rev Mazzella_4.docx (isprambiente.gov.it)

Santana-Méridas, O., González-Coloma, A., and Sánchez-Vioque, R. (2012). Agricultural residues as a source of bioactive natural products. Phytochem. Rev. 11, 447-466. doi: 10.1007/s11101-012-9266-0

Soengas, P., Cartea, M. E., Velasco, P., and Francisco, M. (2018). Endogenous circadian rhythms in polyphenolic composition induce changes in antioxidant properties in brassica cultivars. J. Agric. Food Chem. 66, 5984-5991 doi: 10.1021 /acs.jafc.8b01732

Stalikas, C. D. (2007). Extraction, separation, and detection methods for phenolic acids and flavonoids. J. Sep. Sci. 30, 3268-3295. doi: 10.1002/jssc. 200700 261

Valverde, J., Reilly, K., Villacreces, S., Gaffney, M., Grant, J., and Brunton, N. (2015). Variation in bioactive content in broccoli (Brassica oleracea var. italica) grown under conventional and organic production systems. J. Sci. Food Agric. 95, 1163-1171 doi: 10.1002/jsfa.6804

Van Lanen, S. G., and Shen, B. (2006). Microbial genomics for the improvement of natural product discovery. Curr. Opin. Microbiol. 9, 252-260 doi: 10.1016/j.mib.2006.04.002

Varzakas, T., Zakynthinos, G., and Verpoort, F. (2016). Plant food residues as a source of nutraceuticals and functional foods. Foods 5:88. doi: $10.3390 /$ foods 5040088

Wadhwa, M., and Bakshi, M. P. S. (2013). Utilization of Fruit and Vegetable Wastes as Livestock Feed and as Substrates for Generation of Other Value-Added Products. Roma: FAO

Wang, L. J., and Weller, C. L. (2006). Recent advances in extraction of nutraceuticals from plants. Trends Food Sci. Technol. 17, 300-312. doi: 10.1016/j.tifs.2005.12.004

Zhang, T., Doria, E., Boncompagni, E., Verri, M., Dossena, D., Nielsen, E., et al. (2017). Extraction and evaluation of nutraceutical molecules in wastes of fruit and vegetables. J. Food Nutr. Sci. 4, 74-80. doi: 10.15436/2377-0619.17.1539

Conflict of Interest: The authors declare that the research was conducted in the absence of any commercial or financial relationships that could be construed as a potential conflict of interest.

Publisher's Note: All claims expressed in this article are solely those of the authors and do not necessarily represent those of their affiliated organizations, or those of the publisher, the editors and the reviewers. Any product that may be evaluated in this article, or claim that may be made by its manufacturer, is not guaranteed or endorsed by the publisher.

Copyright ( 2021 Doria, Boncompagni, Marra, Dossena, Verri and Buonocore. This is an open-access article distributed under the terms of the Creative Commons Attribution License (CC BY). The use, distribution or reproduction in other forums is permitted, provided the original author(s) and the copyright owner(s) are credited and that the original publication in this journal is cited, in accordance with accepted academic practice. No use, distribution or reproduction is permitted which does not comply with these terms. 